\title{
GUILLAUME APOLLINAIRE, Teatro
}

\section{Fabio Scotto}

\section{OpenEdition \\ Journals}

\section{Edizione digitale}

URL: https://journals.openedition.org/studifrancesi/44158

DOI: $10.4000 /$ studifrancesi.44158

ISSN: 2427-5856

\section{Editore}

Rosenberg \& Sellier

\section{Edizione cartacea}

Data di pubblicazione: 1 juin 2021

Paginazione: 238-239

ISSN: 0039-2944

\section{Notizia bibliografica digitale}

Fabio Scotto, «GUILlaume Apollinaire, Teatro», Studi Francesi [Online], 193 (LXV | I) | 2021, online dal 01 juillet 2021, consultato il 15 octobre 2022. URL: http://journals.openedition.org/studifrancesi/44158; DOI: https://doi.org/10.4000/studifrancesi.44158

Questo documento è stato generato automaticamente il 15 octobre 2022.

\section{(c) (i) ()}

Creative Commons - Attribuzione - Non commerciale - Non opere derivate 4.0 Internazionale - CC BYNC-ND 4.0

https://creativecommons.org/licenses/by-nc-nd/4.0/ 


\title{
GUILLAUME APOLLINAIRE, Teatro
}

\author{
Fabio Scotto
}

\section{NOTIZIA}

GUILlAUME APOLLINAIRE, Teatro, ed. italiana a cura di F. Bruera, Roma, Carocci editore, 2019, «Lingue e letterature Carocci» 301, 283 pp.

1 Si deve a Franca Bruera, docente all'Università degli Studi di Torino e riconosciuta specialista dell'opera di Apollinaire, questa recente edizione dell'intera sua opera teatrale, la quale va a colmare un vuoto nel panorama editoriale italiano, in cui, fino ad oggi, è prevalsa la traduzione della sua opera in versi e più parziale e occasionale appare quella delle sue prose e delle sue opere drammaturgiche. Nella sua introduzione dal titolo «"È giunta l'ora di riaccendere le stelle": il teatro di Guillaume Apollinaire» (pp. 9-31), la curatrice muove dalla stretta relazione anche biografica, oltre che culturale, del poeta con l'Italia (nacque, come è noto, a Roma, a Trastevere, il 25 agosto 1880), per mostrare la sua fitta rete di rapporti con alcune delle maggiori personalità intellettuali italiane del suo tempo, da Soffici a Savinio, da Magnelli a Ungaretti, che vide in lui «il maggiore poeta di Francia» di quegli anni, anche incoraggiando suoi progetti traduttivi di pubblicazione in francese di poeti italiani, se è a Bologna e a Torino, sul suolo italico, che il poeta apprese a leggere, come si evince da una sua lettera a Raimondi qui menzionata.

2 Da queste molteplici affinità culturali con l'Italia e con Torino muove il progetto editoriale, che fa seguito alle celebrazioni nel 2018 del centenario della morte del poeta, così come, di concerto, della pubblicazione dei Calligrammes e delle Mamelles de Tirésias, dalle quali erano scaturite anche varie altre iniziative quali l'organizzazione del convegno internazionale torinese Métamorphoses d'Apollinaire (22-23 ottobre 2018) e varie altre rappresentazioni teatrali e mostre a Torino e Firenze. Nel seguito del suo testo introduttivo, Bruera si addentra nella genesi e negli sviluppi del teatro di Apollinaire, mostrandone, oltre al connubio iniziale con André Salmon, il carattere fortemente innovativo - se per le Mammelle, per cui aveva pensato a un teatro circolare, 
forgiò la definizione di «drame surréaliste» poi ripresa da André Breton per dare nome al suo movimento d'avanguardia -, i risvolti grotteschi certo tributari anche della lezione della commedia dell'arte, del teatro popolare e del vaudeville, la forza comica e dissacratoria. Si va dalle peripezie clownesche e pre-dadaiste de Il mercante d'acciughe dove Giona raggiunge Parigi dalla Norvegia con un codazzo di commessi poi impiegati in un circo, alle più meditative riflessioni biografiche di Jean-Jacques (ovviamente Rousseau), con la costante volontà di «contrapporsi alla drammaturgia borghese frusta, obsoleta che domina gli anni della Belle Époque» (p. 21), preludio all'esercizio di una «meditazione estetica» di tono meno farsesco, che rivela altresì il suo profondo interesse per la storia del teatro, specie italiano, del quale stila un'antologia critica (Le Théâtre Italien, 1910). Ne scaturiscono la riflessione tragica sulla morte di Color del tempo, con rimandi intertestuali alla lauda drammatica di Jacopone da Todi Donna de Paradiso, o commedie parodiche come Casanova, con il suo concatenarsi progressivo di equivoci e travestimenti.

3 Analogo trasformismo caratterizza poi Le mammelle di Tiresia, la pièce più importante dell'A., rappresentata per la prima volta a Montmartre nel 1917, con la partecipazione attiva di alcune delle figure di maggior spicco del panorama artistico parigino del tempo, da Picasso a Matisse, da Reverdy a Jacob, da Cocteau ad Albert-Birot, con Soupault a fare il suggeritore e Breton, Vaché e Poulenc in sala. Nella trasformazione, per inversione di ruoli sessuali, di Thérèse in Tiresia e nella fecondità femminile del marito, che partorisce, con la sola forza della volontà, quasi 50.000 bambini in un solo giorno, si compie l'idea totale del teatro apollinairiano, attraverso effetti da music-hall, violazioni della separazione fra scena e pubblico ed effetti parodici dell'Edipo re nel solco del teatro jarryano, non senza riferimenti ai moti di protesta del tempo e all'iperbolica interpretazione delle politiche post-belliche di ripopolamento allora in auge, conforme al desiderio d'interessare, divertire e, soprattutto, sorprendere che fu all'origine del suo esprit nouveau.

4 Nella parte conclusiva del suo scritto liminare, la curatrice ben illustra le difficoltà poste dall'originale e i criteri seguiti nel tradurlo, privilegiando una «flessibilità estrema», «la resa della comunicazione fra i diversi linguaggi» e la necessità di prestare «attenzione ai diversi registri linguistici dei personaggi»; un manipolo di esempi ben scelti, dà conto delle soluzioni lessicali attualizzanti per equivalenza adottate (come "“Frigidaire"», la rivista odierna, per "“L'Assiette au beurre"», o come " "grammelot"», per "“agrache"», p. 30), così giustificando sul piano teorico il pensiero soggiacente alla traduzione di un corpus teatrale prevalentemente versificato che qui, pur venendo a mancare il testo francese a fronte, che certo avrebbe consentito di meglio apprezzare il suo arduo compito, risulta comunque di gradevole lettura.

5 Nel suo testo in Appendice "“Far sorgere la vita stessa": Guillaume Apollinaire drammaturgo» (pp. 271-276), P. READ ripercorre l'opera teatrale di Apollinaire sottolineandone la «reinvenzione dello spazio scenico e teatrale» prefigurante «alcuni dei propositi essenziali di Antonin Artaud» (p. 276). Completano il volume una «Bibliografia» selettiva (pp. 277-279) e un «Indice dei nomi» (pp. 281-283). 